\title{
A atuação da sociedade civil nos espaços públicos virtuais para a mediação de projetos de lei sobre mobilidade urbana
}

\author{
Allan Santos \\ Universidade Federal do Rio de Janeiro \\ allansantos29ny@gmail.com
}

Recibido: 31/7/2018 / Aceptado: 26/9/2018

doi: 10.26439/contratexto2018.n030.3151

\begin{abstract}
Resumo. Pensando os ambientes digitais como espaços públicos virtuais de diálogos e disputas para a produção da hegemonia e obtenção do consenso, o artigo problematiza o conceito gramsciano de "sociedade civil" à luz do ecossistema existencial contemporâneo que Muniz Sodré $(2002,2014)$ define como "midiatização generalizada" ou "bios virtual", questionando a existência de mecanismos que possibilitem a atuação de organizações da sociedade civil nestes espaços para a mediação política entre cidadãos e o Estado na busca por formas mais humanas de se viver. Em seguida, pensando a comunicação como organização do comum, propomos uma reflexão sobre as cidades como espaços privilegiados de negociação de sentidos partilháveis e a centralidade da mobilidade urbana na configuração dos modos como nos comunicamos na cidade e com a cidade. Na esteira deste raciocínio, argumentamos que melhorias em questões relativas à circulação de pessoas e aos sistemas de transportes podem contribuir para a humanização dos centros urbanos. Por último, investigamos como o aplicativo MUDAMOS tem atuado nos espaços públicos virtuais para a mediação do processo de construção de projetos de lei de iniciativa popular sobre mobilidade urbana que visam restituir a noção de cidade como um bem comum em João Pessoa, Paraíba, Brasil.
\end{abstract}

Palavras-chave: sociedade civil / espaços públicos virtuais / cidade / mobilidade urbana / MUDAMOS 


\title{
La actuación de la sociedad civil en los espacios públicos virtuales para la mediación de proyectos de ley sobre movilidad urbana
}

\begin{abstract}
Resumen. Pensando los ambientes digitales como espacios públicos virtuales de diálogos y disputas para la producción de la hegemonía y obtención del consenso, el artículo problematiza el concepto gramsciano de "sociedad civil" a la luz del ecosistema existencial contemporáneo que Muniz Sodré (2002, 2014) define como "mediatización generalizada" o "bios virtual", cuestionando la existencia de mecanismos que posibiliten la actuación de organizaciones de la sociedad civil en estos espacios para la mediación política entre ciudadanos y el Estado en la búsqueda de formas más humanas de vivir. A continuación, pensando la comunicación como organización de lo común, proponemos una reflexión sobre las ciudades como espacios privilegiados de negociación de sentidos compartidos y la centralidad de la movilidad urbana en la configuración de los modos como nos comunicamos en la ciudad y con la ciudad. En la rama de este razonamiento, argumentamos que mejoras en cuestiones relativas a la circulación de personas y los sistemas de transporte pueden contribuir a la humanización de los centros urbanos. Por último, investigamos cómo la aplicación CAMBIO ha actuado en los espacios públicos virtuales para la mediación del proceso de construcción de proyectos de ley de iniciativa popular sobre movilidad urbana que apuntan a restituir la noción de ciudad como un bien común en João Pessoa, Paraíba, Brasil.
\end{abstract}

Palabras clave: sociedad civil / espacios públicos virtuales / ciudad / movilidad urbana / aplicación CAMBIO 


\section{The role of civil society in virtual public spaces for the mediation of urban mobility bills}

Abstract. Thinking of digital environments as virtual public spaces of dialogue and dispute for constructing hegemony and obtaining consensus, the article problematizes the gramscian concept of "civil society" in the light of the contemporary existential ecosystem that Muniz Sodré (2002, 2014) defines as "generalized mediatization" or "virtual bios". This is carried out by questioning the existence of mechanisms that allow the performance of civil society organizations in these spaces for political mediation between citizens and the State in the search of more human ways of living. Then, thinking of communication as the organization of the common, we propose a reflection of cities as privileged spaces for negotiation of shared meanings, and the centrality of urban mobility in shaping the ways we communicate in the city and with the city. Based on this reasoning, we argue that improvements in issues relating to the movement of people and transport systems may contribute to the humanization of urban centers. Finally, we investigate how the MUDAMOS application has acted in the virtual public spaces for the mediation of the process for preparing popular-initiative bills on urban mobility that aim to restore the notion of city as a common good in João Pessoa, Paraíba, Brazil.

Keywords: civil society / virtual public spaces / city / urban mobility / MUDAMOS app 


\section{Introdução}

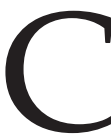

ontemporaneamente um número expressivo de atividades coletivas, convívios e trocas tradicionalmente desenvolvidas em espaços públicos - ruas, praças, parques, cafés, bares e espaços de convivência - estão sendo gradativamente deslocadas para os ambientes de sociabilidade digital. Neste contexto, a discussão e a elaboração colaborativa de soluções para desafios de interesses comuns passam a ser midiatizadas por tecnologias virtuais e se desenvolvem, em grande maioria, através das redes sociais de Internet. No presente trabalho, questionamos a existência de mecanismos que possibilitam a atuação da sociedade civil nos espaços públicos virtuais para a mediação política entre cidadãos e o Estado na disputa por formas mais humanas de se viver. A partir da reflexão teórica e da análise do funcionamento do aplicativo MUDAMOS ${ }^{1}$, argumentamos que melhorias em problemas relacionados à mobilidade urbana podem contribuir para a humanização e a democratização das cidades.

$\mathrm{O}$ artigo é dividido em três partes. No primeiro momento, deslocamos o conceito gramsciano de "sociedade civil" para o ecossistema existencial contemporâneo que Muniz Sodré (2002, 2014) define como "midiatização generalizada" ou "bios virtual". Neste contexto epistemológico, observamos que, por um lado, "não faltam os argumentos indicativos de que estaríamos vivendo uma era de pós-sociedade civil ou então de desaparecimento da política em favor da estética" (Sodré, 2014, p. 180). Por outro, notamos que mesmo diante dos obstáculos apresentados pela midiatização dos espaços públicos e das práticas políticas, algumas organizações têm conseguido agir a favor da produção de mecanismos que possibilitem a movimentação de cidadãos comuns na direção da garantia dos seus direitos sociais.

Em seguida, a partir da perspectiva sodreana $(2002,2014,2017)$ que compreende a comunicação como organização do comum, propomos uma análise das cidades como espaços privilegiados de aprofundamento dos sentidos partilháveis contemporâneos, ou seja, ambientes de negociações, conflitos e construções de significados entre atores sociais. Seguindo essa linha de pensamento, o pesquisador sobre questões relativas à cidade e mobilidade, Leandro Carmelini (2016), sugere que a circulação e os sistemas de transportes se configuram como importantes elementos histórico-políticos dos espaços urbanos -disputados pelo Estado, mercado e corpos- que participam direta e profundamente dos processos de espacialização

1 Site do MUDAMOS: https://www.mudamos.org/ 
e subjetivação. Ainda nesta seção sintetizamos o aparato de diretrizes federativas brasileiras que instituem a Política de Desenvolvimento Urbano e a Política Nacional de Mobilidade Urbana, atentando para os limites e obstáculos que esses dispositivos legais encontram para as suas implementações nos municípios.

$\mathrm{Na}$ terceira parte do artigo questionamos a existência de modelos alternativos que ofereçam oportunidades de engajamento popular nos debates sobre problemas relacionados à mobilidade urbana, o que permite que essas questões se tornem de fato objetos de políticas concretas. É a partir dessa perspectiva que tomamos como estudo de caso o aplicativo MUDAMOS e investigamos de que forma essa iniciativa tem se apropriado das tecnologias digitais para o fomento de práticas de participação cidadã na construção de políticas urbanas. Compreendendo que a procura por soluções para os desafios impostos pelas cidades não pode ser uma atividade exclusiva das instituições governamentais e dos agentes políticos, analisamos como esta plataforma digital -desenvolvida por uma organização da sociedade civil- oferece oportunidades de atuação popular nas disputas pelo comum humano que contemporaneamente se realizam, em grande medida, nos espaços públicos virtuais.
De modo a melhor explorarmos os problemas de pesquisa e atingirmos os objetivos propostos, dividimos a metodologia em três etapas complementares. Inicialmente, mapeamos o funcionamento da plataforma digital MUDAMOS (concepção, desenvolvimento, modo de funcionamento e análise de cinco projetos de lei de iniciativa popular propostos na cidade brasileira de João Pessoa, Paraíba). Em seguida, assistimos ao vídeo da Virada Legislativa (Desafio Mobilidade Urbana) ${ }^{2}$ que foi um evento pioneiro -realizado em 20 de outubro de 2017 pelo Instituto de Tecnologia e Sociedade do Rio de Janeiro (ITS Rio) em parceria com a Câmara Municipal de João Pessoa (CMJP)- para o debate e proposição coletiva de projetos de lei sobre mobilidade urbana nesta cidade. Por último, em 28 de fevereiro de 2018, realizamos uma entrevista com os seguintes membros do ITS Rio (Instituto de pesquisa científica responsável pela concepção e desenvolvimento do MUDAMOS): Marco Konopacki, coordenador de projetos na linha de Democracia e Tecnologia; Debora Albu, pesquisadora da mesma linha; e Victor Vicente, coordenador de comunicação. A entrevista durou aproximadamente 2 horas em um formato de perguntas e respostas abertas, ou seja, cada membro da equipe respondeu às perguntas de suas respectivas áreas de expertise no projeto.

2 Transmitido ao vivo pela TVCâmara João Pessoa e disponível para visualização em https://goo. gl/Uvdbrw 


\section{Sociedade Civil Midiatizada}

Segundo o cientista político Alvaro Bianchi (2017), ainda é possível nos dias de hoje estabelecer muitos diálogos com o pensamento de Antonio Gramsci (1891-1937), ao ser este um campo internacional e interdisciplinar de estudos, vasto e diversificado. No que tange aos aspectos centrais da produção intelectual do filósofo italiano, Carlos Nelson Coutinho (1989) -um dos maiores especialistas em Gramsci- enfatiza que o conceito de "sociedade civil" é um elemento essencial na determinação da especificidade da teoria política gramsciana. É importante observar que o pensador marxista usa em suas notas o conceito como foi entendido por Hegel (1770-1831), ou seja, no sentido de hegemonia política e cultural de um grupo social sobre toda a sociedade, distinguindo-o do sentido que lhe dão os católicos, para quem a sociedade civil, ao contrário, é a sociedade política ou o Estado, em oposição à sociedade familiar e à Igreja (Liguori e Voza, 2017).

A título de contextualização histórica, com as revoluções liberais e a intensificação dos processos de sociabilização da participação política no fim do século XIX, Gramsci propôs uma renovação do marxismo a partir de uma relação de continuidade e superação dialética com as ideias de Marx (1818-1883). Desta forma, o autor concebeu uma "teoria ampliada do Estado", na qual o caráter classista nas sociedades capitalistas mais complexas não se explicitava apenas através dos aparelhos repressivos do Estado, mas também a partir da articulação entre tais aparelhos e os "aparelhos privados de hegemonia", isto é, entre a sociedade política e a sociedade civil (Coutinho, 1989). É neste sentido que a teoria gramsciana conserva o núcleo central do marxismo, ao mesmo tempo que incorpora novas determinações geradas pelos acontecimentos histórico-sociais da época em que foi desenvolvida: "Gramsci não inverte nem nega as descobertas essenciais de Marx, mas 'apenas' as enriquece, amplia e concretiza, no quadro de uma aceitação plena do método do materialismo histórico" (Coutinho, 1989, p. 74). Segundo afirma o próprio Gramsci no volume 2 das Cartas do Cárcere:

Este estudo também leva a certas determinações do conceito de Estado, que, habitualmente, é entendido como sociedade política (ou ditadura, ou aparelho coercitivo, para moldar a massa popular segundo o tipo de produção e a economia de um dado momento), e não como um equilíbrio da sociedade política com a sociedade civil (ou hegemonia de um grupo social sobre toda a sociedade nacional, exercida através das organizações ditas privadas, como a igreja, os sindicatos, as escolas etc.). (Coutinho, 2011, p. 267)

Segundo Coutinho (1989), neste cenário de mutações sociais geradas pela sociabilização da participação política, os homens já não são levados a realizar as ações, que irão desembocar na construção e reprodução da ordem social, pela coerção e sim pela persuasão, pela expressão da opinião pública e pela 
obtenção do consenso, ou seja, por mecanismos de controle que se manifestam a partir do diálogo: "Diálogo é, assim, a penetração (não necessariamente linguística) na 'razão' (logos) ou narrativa constitutiva do comum" (Sodré, 2014, p. 261). Refletindo sobre a teoria política gramsciana, o pesquisador brasileiro Eduardo Granja Coutinho (2014, p. 15) sugere que é pela interação semiótica, pela reelaboração e compartilhamento dos signos, que os sujeitos constroem suas identidades e organizam a sua visão de mundo representando a realidade a partir de uma determinada perspectiva e de acordo com seus interesses, anseios e expectativas. Com efeito, é pela comunicação que se formam e transformam ideologias que agem ética e politicamente na transformação da história.

Contemporâneo de Gramsci e considerado o filósofo do diálogo, Mikhail Bakhtin (1895-1975) ressalta em toda a sua obra o aspecto social-normativo da comunicação discursiva e as relações de reciprocidade entre linguagem e construção ideológica. Para o pensador russo, os valores comuns são construídos por meio do diálogo e das negociações por sentidos sígnicos e, portanto, são resultados intersubjetivos da interação dialógica com significados previamente apreendidos e conectados a partir de elos complexamente organizados. Deste modo, os enunciados não são atos individuais e sim construções históricas, culturais e sociais que se constroem a partir das relações dos falantes com outros participantes do processo comunicacional.
De acordo com esta concepção dialógica da comunicação discursiva, o outro não serve apenas na função de ouvinte que compreende passivamente $\mathrm{o}$ falante, pois "toda compreensão da fala viva, do enunciado vivo é de natureza ativamente responsiva" (Bakhtin, 1992, p. 271). A noção bakhtiniana de que o ouvinte, quando percebe e compreende o significado linguístico do discurso, assume uma "compreensão responsiva ativa" será futuramente recuperada pela noção de "mediações socioculturais" que propõe analisar o que acontece na recepção das mensagens para compreender como as pessoas ressignificam ativamente os conteúdos midiáticos e de que forma os discursos hegemônicos influenciam as relações dos sujeitos entre si e com o mundo em que vivem. Segundo esta linha de pensamento, os meios de comunicação não são meros mecanismos para se realizar a alienação em um público passivo e sim dispositivos que passam a disputar espaço com a sociedade civil e a esfera pública como formas de produção dialógica de sentidos comuns e de obtenção de consenso.

Entretanto, em face das mutações qualitativas em termos de configuração social por efeito da articulação da tecnologia eletrônica com a vida humana e do funcionamento articulado das tradicionais instituições sociais com a mídia, o conceito de mediação -de origem hegeliana e introduzido nas análises culturalistas da mídia por críticos ingleses, conforme Raymond Williams, e apropriada como categoria analítica privilegiada da sociologia da cultura 
por pesquisadores latino-americanos, como Jesus Martin Barbero e OroscoGómez- tende a perder o protagonismo nos estudos comunicacionais e cede seu lugar para outras proposições teóricas. Segundo Sodré (2014, p. 110), telefones celulares, laptops e outros dispositivos de conexão com a internet não apenas mudaram o panorama do consumo de mídia como também criaram tecnologias próprias de mediação. Conforme verificaremos na análise do aplicativo MUDAMOS na seção 4 deste artigo, até no nível das políticas públicas a mediação da sociedade civil entre o Estado e os diferentes grupos sociais passa a ser gradativamente delegada às regulações técnicas e empresariais trazidas pelos dispositivos digitais.

Tendo em vista que as relações sociais e de poder, os processos de participação política, os regimes de visibilidade e a cognição humana estão imersos em um universo governado pelas tecnologias da comunicação e da informação, torna-se fundamental deslocarmos as perspectivas gramsciana de "sociedade civil" e bakhtiniana de "dialogismo" para a contemporaneidade das redes sociotécnicas. É neste contexto epistemológico que procuramos compreender o processo de midiatização das práticas políticas, pensando a Internet como um espaço público virtual de diálogo e negociações para a organização da hegemonia e a obtenção do consenso dos grupos subalternos.

Segundo Muniz Sodré (2014), renomado teórico brasileiro da comunicação, a midiatização é uma elaboração conceitual criada para explicar essa nova instância de orientação da realidade capaz de permear as relações sociais por meio do desenvolvimento acelerado dos processos de convergência midiática, constituindo uma forma virtual ou simulativa de vida. Apesar de que a espacialidade configurada como midiatização é um ponto de partida para a investigação dos processos comunicacionais contemporâneos, ela revela-se ainda insuficiente por sua abstração com referência às condições concretas e diferenciadas de vida ou pela ausência de orientação existencial como a que comparece no conceito aristotélico de bios ${ }^{3}$.

Pensando a comunicação na contemporaneidade de modo amplo e crítico, Sodré $(2002 ; 2014)$ propõe a teoria do processo constitutivo do bios virtual,

3 Em Ética a Nicômaco, Aristóteles distingue três gêneros de existência (bios) na Polis: bios theoretikos (vida contemplativa), bios politikos (vida política) e bios apolaustikos (vida prazerosa, vida do corpo). Partindo da classificação aristotélica, Sodré concebe o modo de presença do sujeito contemporâneo no mundo como um quarto bios, o que implica uma transformação das formas tradicionais de sociabilização, além de uma nova tecnologia perceptiva e mental. Implica, portanto, um novo tipo de relacionamento do indivíduo com referências concretas ou com o que se tem convencionado designar de verdade, ou seja, uma nova condição antropológica (Sodré, 2002). 
ou seja, um novo ecossistema existencial no qual a mídia atua como motor semiótico da representação em resposta às necessidades de flexibilização e instantaneidade do capitalismo financeiro transnacional. Nessa forma de existência, o que na política se experimenta como puro ethos é absorvido pelas técnicas de consenso e controle que confluem para a mídia. Da mídia para o público não parte apenas influência normativa, mas principalmente emocional e sensorial, com o pano de fundo de uma estetização generalizada da vida social, na qual identidades pessoais, comportamentos e até juízos de natureza supostamente ética passam pelo crivo de uma invisível comunidade do gosto. Nas palavras do autor:

Isto é propriamente o bios virtual, uma ambiência magneticamente afetiva, uma recriação tecnoestética do ethos, capaz de mobilizar os humores ou estados de espírito dos indivíduos, reorganizando seus focos de interesse e de hábitos, em função de um novo universo menos psiquicamente "interiorizado" e mais temporalmente relacionado ou conectado pelas redes técnicas. (Sodré, 2014, p. 252)

Ainda segundo a crítica sodreana, uma vez que as organizações multinacionais financiam o processo de midiatização das práticas políticas, as instituições tradicionalmente responsáveis pela elaboração e difusão das ideologias perdem progressivamente a legitimidade. O Estado tem deslocada a sua centralidade como administrador dos bens públicos (passando a funcionar a partir da lógica de privatização das ferramentas com que se lida com o comum na contemporaneidade) e os sentidos passam a ser organizados por imagens, o que causa alterações das subjetividades de uma forma ampla. Desde o pós-Segunda Guerra Mundial, o fenômeno da midiatização vem alterando costumes, crenças, afetos e a própria estruturação das percepções. No entanto, sob o feitio neoliberal, assumido pela globalização no fim do milênio, exacerbou-se a dimensão imperial do poder, implicando em uma qualificação particular de vida e um novo modo de presença dos sujeitos no mundo. Neste passo:

A hegemonia do capitalismo financeiro, da cultura algorítmica e do biopoder (midiatização) dá margem à hipótese de emergência de uma espécie de sociedade incivil, onde mutações socioeconômicas desconstroem o clássico comum, assim como os laços representativos entre povo e Estado -- portanto, a política em sua forma parlamentar -- em benefício de formas tecnológicas e mais abstratas de controle social. Essas mutações constituiriam evidências do evanescimento da sociedade civil, tal como reinterpretada por Gramsci, na esteira do pensamento hegeliano. (Sodré, 2018)

Em um contexto contemporâneo de desconstrução do clássico comum pelas mutações socioeconômicas e tendo em vista que "há uma dimensão comum nas cidades" (Carmelini, 2017, p. 13), como reconfigurar os espaços urbanos de modo a resgatar a sua dimensão humana? Para Pacheco (2013), a ampliação dos espaços de discussão sobre mobilidade urbana e a construção de políticas públicas de 
valorização de pedestres e modais não motorizados apontam em direções que já trouxeram resultados para muitas cidades do mundo: desde Copenhague (reconhecida mundialmente por suas políticas de priorização de pedestres, ciclistas e transporte coletivo), passando por Londres (que ao aderir às "zonas 30" viu o número de acidentes cair $40 \%$ ), até Nova York (responsável pela construção de 480 km de ciclovias entre 2008 e 2013). Na América Latina, Bogotá alargou as calçadas, priorizou o transporte público e aumentou a rede cicloviária em 350 km (Pacheco, 2013). Segundo Enrique Peñalosa, urbanista e prefeito da capital colombiana entre 1998 e 2001, "remodelar as cidades por meio do incentivo ao uso dos espaços públicos, garantindo espaço e segurança aos pedestres, melhora a mobilidade urbana e é o caminho para um desejo comum: cidades mais humanas".

\section{Comunicação, Cidade e Mobilidade Urbana}

Compreendemos que as cidades não constituem um monopólio das pesquisas do campo comunicacional, sendo também objetos empíricos de estudos da arquitetura, engenharia, design, economia e psicologia. No entanto, é a maneira como as identificamos e analisamos que lhe concedem uma dimensão comunicativa. Segundo a comunicóloga brasileira Vera França (2016), ao começarmos a estudar objetos e práticas pelo viés da comunicação criamos o objeto comunicacional. Por tanto, para a pesquisadora são necessárias, para desenvolver uma pesquisa em comunicação, uma discussão e uma tomada de posição sobre o que estamos entendendo como comunicação: "É uma determinada concepção de comunicação que organiza nosso olhar sobre um objeto (uma prática) e define as questões que podemos formular sobre ele; que orienta, portanto, nosso processo de conhecimento"' (França, 2016, p. 157).

Neste trabalho, partimos da perspectiva sodreana $(2002,2014,2017)$ que compreende a comunicação como um campo epistemológico com características próprias e cujo objeto de estudo não se restringe à mídia, sendo esta apenas um dispositivo técnico daquilo que de fato deve ser tratado pela comunicação: a organização do comum humano. Para o teórico, os seres humanos são comunicantes, não porque falem (atributo consequente ao sistema linguístico), mas porque relacionam ou organizam mediações simbólicas - de modo consciente ou inconsciente - em função de um comum a ser partilhado.

Muito antes do predomínio publicitário e acadêmico dos modelos funcionalistas da sociologia da comunicação norteamericana, esse entendimento lato da comunicação vigorava no campo do pragmatismo filosófico (em John Dewey e Charles Sanders Peirce, principalmente), assim como na reflexão urbana da Escola de Chicago, onde a comunicação podia aparecer tanto como a vinculação básica que permitia prever comportamentos sociais quanto como a vinculação que, além da associação 
puramente fisiológica, dava ensejo à dimensão moral. (Sodré, 2017, p. 197)

Ainda segundo Sodré (2017), o comum - o "para além" das diferenças entre culturas ou modos de existência advém no processo de inteligibilidade de um sentido potencialmente partilhável. É o comum que faz acontecer a comunicação enquanto dimensão vinculativa ou relacional, ela faz aparecer as coerências internas de cada cultura para, em seguida, torná-las comunicáveis. Os pensadores franceses Dardot e Laval (2017) propõem refundar de maneira rigorosa este conceito, sugerindo que o comum é um princípio político: uma força contrária à racionalidade neoliberal e à lógica da concorrência que têm estruturado as mentalidades e os comportamentos, tanto dos governantes quanto dos governados, especialmente a partir da década de 1980. Segundo os autores, longe de ser pura invenção conceitual, a "reinvindicação do comum" é a fórmula de movimentos e correntes de pensamento que pretendem opor-se à tendência dominante de nossa época: a da ampliação da propriedade privada a todas as esferas da sociedade, da cultura e da vida.

Tendo em vista a centralidade das cidades na configuração dos significados comuns, faz sentido que a comunicação social, enquanto "ciência síntese reflexiva do século xxi"4, contemple esses espaços de organização da diversidade processual humana e trascenda o paradigma positivista-funcionalista que limita as práticas comunicacionais aos processos de trocas informacionais e resume os seus dispositivos ao conceito de mídia: "A comunicação se refere primordialmente a um comportamento ou a uma ação simbólica de vincular ou pôr em comum partes diferentes no interior de um sistema" (Sodré, 2017, p. 177). Neste sentido, as cidades podem ser compreendidas como sistemas comunicacionais, nos quais vidas são cotidianamente afetadas, relações são tecidas e subjetividades são moldadas em função da forma como esses espaços são constituídos. Segundo a professora da Escola de Comunicação da Universidade Federal do Rio de Janeiro, Janice Caiafa:

Há um espaço de comunicação, um trânsito que escoa pelas vias urbanas diversas - transeuntes ao longo das ruas, veículos que os conduzem, informação ao longo de cabos ou carreada por dispositivos móveis. Formas de circulação e comunicação seguem deslocando, por vezes, as anteriores ou sendo adaptadas por elas, produzindo experiência, afetando o espaço construído e gerando formas de sociabilidade e de subjetivação. (Caiafa, 2017, p. 1)

4 Segundo Barbosa (2016), as pesquisas de comunicação seguem quase que obrigatoriamente os processos históricos que denominamos como contemporâneos, o que faz da comunicação uma história do tempo passando. 
Abordando especificamente a relação entre comunicação e transporte, o professor da Universidade de Londres, David Morley (2017), também critica abordagens contemporâneas mais restritas da comunicação que se concentram exclusivamente nas dimensões simbólica, institucional e tecnológica da mobilidade de informação, em detrimento da análise do movimento de pessoas e mercadorias. Para o autor, definições mais antigas de comunicação abrangiam não apenas os fluxos de signos, mas também o campo dos estudos de transporte: "Foi nesse espírito que Marx e Engels definiram comunicação de forma suficientemente ampla para incluir o movimento de mercadorias, pessoas, informações e capital" (Morley, 2017, p. 10). O seu argumento é a favor de uma maior integração entre os campos da comunicação e dos estudos de transporte, a partir de um paradigma que coloque efetivamente questões de mídia e comunicação no quadro mais amplo de seus contextos e configurações materiais: “Embora as novas dimensões virtuais de nosso mundo tenham consideráveis consequências, a geografia material, longe de estar 'morta', ainda requer a nossa cuidadosa atenção" (Morley, 2017, p. 13).

Diante de um cenário que consideram como sintomático da "falência do projeto de cidade", os pesquisadores brasileiros da comunicação Gabbay e Paiva (2017) reúnem argumentos científicos que sustentam a necessidade de reflexão sobre uma "nova cidade humana". Dentre eles, a comprovação que morar perto do tráfego pesado de veículos aumenta a possibilidade de casos de demência
(Parkinson, Alzheimer e esclerose múltiplas) e a constatação de que o nível de poluição aérea e sonora produz, além de problemas respiratórios e cardíacos, mutações cerebrais. Ou seja, "a poluição sonora, visual e ambiental constitui uma pletora de fatores degradantes das formas de vida e de trocas simbólicas nas grandes cidades" (Gabbay e Paiva, 2017, p. 7).

Segundo os autores, para concebermos um nível de convivialidade possível nos centros urbanos é fundamental problematizar os matizes da cidade atual que já demonstram, há algumas décadas, a impossibilidade de prosseguir com os modelos adotados, até então, de exclusão, invisibilidade e agressividade. Eles alertam que este tipo de arquitetura social "tende a apartar, deprimir e desestruturar a produção do comum, ou seja, do que vai necessitar da invenção ou recuperação de espaços propícios ao encontro, à troca de olhares e ao contato de corpos" (Gabbay e Paiva, 2017, p. 2). Para Dardot e Laval (2017). A instituição da propriedade privada, ao excluir as coisas do uso comum, nega a cooperação, sem a qual nada seria produzido; ignora o tesouro comum acumulado, no qual toda e qualquer riqueza nova encontra suas condições de possibilidade. $\mathrm{Na}$ esteira deste raciocínio, refletimos sobre possíveis caminhos para a restituição de uso comum das cidades, argumentando que melhorias em questões relativas à circulação de pessoas e aos sistemas de transportes podem contribuir para a humanização e a democratização desses espaços. 
Partindo de uma visão de urbanidade como um modo de vida mais relacionado aos fluxos que às formas, alicerçada mais em limiares e passagens que em fechamentos e fixações, Leandro Carmelini (2017) compreende o movimento e a circulação como elementos centrais da genealogia urbana. Para o pesquisador de cidades, a circulação -a movimentação dos corpos no espaço- é um importante elemento histórico-político das cidades e os modais de transportes são ferramentas conectivas singulares, que atuam ativamente na produção dos corpos que movem e na mediação dos encontros. Neste contexto, ao moldarem, estratificarem e modularem a mobilidade - que concede acessos, ao mesmo tempo que impede que cidadãos transitem livremente e se relacionem com certos locais, objetos, serviços e outros corpos-, os modos de deslocamento e a materialidade cotidiana dos meios de transporte influem nas trocas e na organização do comum nas cidades. Em outras palavras, a circulação urbana é fundamental para a configuração e a reprodução das diferentes maneiras como nos comunicamos na cidade e com a cidade.

A partir de uma perspectiva histórica, observamos que entre os séculos XIX e xx os meios de transportes motorizados, sobretudo os modais rodoviários individuais, ganharam protagonismo na sociabilidade urbana, se tornando peças elementares no aprofundamento do modelo de cidade ocidental e do ideário moderno de circulação: "É através deles que as coisas e as pessoas passam a ir de um ponto ao outro, articular encontros, acessar os espaços" (Carmelini, 2017, p. 9). O "progresso" exigiu transformações qualitativas na paisagem urbana, reconfigurando cidades inteiras, alargando os perímetros territoriais, construindo vias asfaltadas e implementando extensas vias férreas. Para garantir o fluxo cada vez mais veloz de motocicletas, carros, ônibus, trens e metrôs, foi necessário que calçadas, espaços públicos de convivência e vias de deslocamento de transportes não motorizados fossem significantemente restritos, reduzindo a movimentação livre de pedestres, limitando a potência da diversidade dos encontros e tornando os espaços públicos cada vez mais homogêneos.

Talvez segregar ou dificultar não seja mesmo o objetivo explícito da estratégia, mas no momento em se impõe ao todo urbano tamanha funcionalidade, o que não está conforme este escopo estratégico predefinido - seja um corpo estranho, uma rota paralela, errante, ou mesmo um rumo ou uma pausa indeterminada - acaba tendo dificuldades de se manifestar. (Carmelini, 2017, p. 12)

Como reconfigurar este paradigma moderno da circulação tendo em mente a dimensão humana das cidades? Como fazer com que os habitantes dos grandes centros urbanos se sintam convidados a caminhar, usar transportes coletivos e reocupar os parques, praças e áreas de uso comum? Compreendendo que a configuração espacial das cidades influencia as maneiras pelas quais os cidadãos circulam e habitam esses ambientes, o governo brasileiro tem 
implementado diretrizes para guiar os municípios no planejamento da mobilidade urbana e na construção de espaços públicos de qualidade que afetem positivamente o modo como a população se desloca cotidianamente. Dentre os princípios da legislação brasileira estão a priorização dos modos de transporte ativos sobre os motorizados, o estímulo ao uso do serviço de transporte público coletivo sobre o transporte individual, além da implementação de calçamentos adequados, ciclovias, conexões para ciclistas, arborização das ruas e fachadas de prédios mais convidativas.

Neste sentido, a Constituição Federal de 1988 estabelece no seu artigo 21, inciso XX, que compete à União "instituir diretrizes para o desenvolvimento urbano, inclusive habitação, saneamento básico e transportes urbanos". Mais adiante - título VII, capítulo II - a Carta Magna brasileira trata exclusivamente da política urbana, determinando que esta tem por objetivo ordenar o pleno desenvolvimento das funções sociais da cidade e garantir o bem-estar de seus habitantes, devendo ser executada pelo Poder Público Municipal. De acordo com o $\S 1^{\circ}$ do artigo 182: o plano diretor, aprovado pela Câmara Municipal, obrigatório para cidades com mais de vinte mil habitantes, é o instrumento básico da política de desenvolvimento e expansão urbana. No entanto, a Política de Desenvolvimento Urbano de que trata a Constituição -assim como o Estatuto da Cidade (Lei 10.257, de 10 de julho de 2001)- foca-se no uso da propriedade urbana em prol do bem coletivo como meio de garantir a ordenação das funções sociais das cidades sem, no entanto, tratarem especificamente da questão da circulação de pessoas e dos transportes.

De forma ainda tímida, o Código de Trânsito Brasileiro (Lei 9.503, de 23 de setembro de 1997) determina a obrigação do "maior cuidar do menor". De acordo com o artigo 29, item XIII, $\S 2^{\circ}$ : “(...) em ordem decrescente, os veículos de maior porte serão sempre responsáveis pela segurança dos menores, os motorizados pelos não motorizados e, juntos, pela incolumidade dos pedestres". Entretanto, é somente após 24 anos da promulgação da Constituição que a Presidência da República instituiu a Política Nacional de Mobilidade Urbana - PNMU (Lei 12.587, de 3 de janeiro de 2012). A Lei funciona como um instrumento da Política de Desenvolvimento Urbano Brasileira, instituindo as diretrizes para que as cidades possam planejar e guiar ações políticas de mobilidade urbana mais sustentáveis, ao mesmo tempo que concede aos municípios segurança jurídica para construírem infraestruturas necessárias para a concretização de seus projetos.

Para cumprir os seus objetivos, a PNMU determina a elaboração de Planos de Mobilidade Urbana para cidades com mais de 20 mil habitantes como requisito para o repasse de recursos orçamentários federais. Segundo a Lei 12.587/12, os Planos Municipais responsáveis por estabelecer as condições em que se realizam os deslocamentos de pessoas e cargas no espaço urbano devem priorizar os pedestres, os modais 
não motorizados e o transporte público coletivo. Observamos que eventuais ações e investimentos das Prefeituras podem ser contestados, caso eles venham a contrariar as diretrizes fixadas pela Lei. A orientação também destaca que o planejamento deve estar ligado às regulações urbanísticas, metas ambientais e princípios da acessibilidade universal da cidade. Isso implica uma ampla revisão das formas com as quais as cidades contemporâneas têm lidado com os desafios de mitigar os custos socioeconômicos e ambientais engendrados pela mobilidade.

Embora exista um aparato de leis federativas no Brasil para a orientação do desenvolvimento de cidades mais humanas e sustentáveis, esses dispositivos legais encontram barreiras - legislativas, econômicas e mercadológicas - para, de fato, serem implementados. Focando no âmbito das cidades, questionamos a existência de modelos alternativos que ampliem os espaços de discussão sobre problemas relacionados à circulação de pessoas e transportes, possibilitando que essas questões se tornem objetos de políticas concretas. Como, mesmo diante dos obstáculos apresentados pela midiatização dos espaços públicos e das práticas políticas, organizações da sociedade civil podem atuar nos espaços públicos virtuais para a mediação política entre cidadãos e o Estado na disputa por direitos sociais e formas mais humanas de se viver.

\section{Mediando MUDANÇAS para a Mobilidade Urbana em João Pessoa}

Tendo como base a reflexão teórica sobre o processo de midiatização das práticas políticas a reboque dos interesses do capitalismo financeiro transnacional e das possíveis contribuições de melhorias em problemas relacionados à mobilidade urbana para a humanização e a democratização das cidades, investigamos como o aplicativo MUDAMOS -concebido e desenvolvido por um organismo da sociedade civil- tem mediado a relação entre os eleitores e a Câmara Municipal de João Pessoa para a construção de projetos de lei de iniciativa popular sobre mobilidade urbana.

A partir da experiência adquirida com a prática de construção do "Marco Civil da Internet" -referência internacional de legislação criada via consulta pública online-o Instituto de Tecnologia e Sociedade do Rio de Janeiro (ITS Rio) ${ }^{5}$ desenvolveu a Plataforma Brasil, que após o primeiro ciclo de debates sobre a reforma política brasileira em 2015, foi rebatizada para MUDAMOS. O projeto foi financiado exclusivamente com o prêmio de R\$1,5 milhão do Desafio de Impacto Social Google 2016 e disponibilizado para dispositivos Android e iOS

5 Site: https://itsrio.org/pt/home/ 
em 30 de março de 2017 (tendo obtido mais de 300 mil downloads em apenas sete dias de funcionamento). Ao desenvolverem tecnologias digitais próprias de mediação da sociedade civil entre o Estado e os diferentes grupos sociais, a ferramenta permite que cidadãos assinem eletronicamente projetos de lei de iniciativa popular pelo telefone celular, o que promove uma forma da população participar na construção de leis nacionais, estaduais e municipais.

A Constituição Federal Brasileira de 1988 -parágrafo 2 do artigo 61, regulamentado pela lei 9709 de 1998- versa que a iniciativa popular pode ser exercida pela apresentação à Câmara dos Deputados de projeto de lei subscrito por, no mínimo, um por cento do eleitorado nacional, distribuído pelo menos por cinco Estados, com não menos de três décimos dos eleitores de cada um deles. No entanto, o exercício deste mecanismo de democracia direta tem sido limitado pelas dificuldades logísticas que impõem coletar e verificar a autenticidade de um grande volume de assinaturas em papel, fazendo com que os projetos populares dependam de um parlamentar para adotá-los e apresentá-los como de sua própria autoria dispensando, assim, a validação manual das assinaturas.

Desde 1988, somente quatro iniciativas foram aprovadas e transformadas em leis brasileiras: a Lei 8.930/1994, que tipifica novos crimes hediondos como homicídio; a Lei 9.840/1999 - Lei contra a Compra de Votos; a Lei 11.124/2005 - Fundo Nacional de
Habitação de Interesse Social; a Lei Complementar 135/2010 - Lei da Ficha Limpa (Blume, 2015). De acordo com Márlon Reis, jurista brasileiro e um dos idealizadores do MUDAMOS, a ideia para o aplicativo surgiu a partir de suas experiências negativas à frente dos projetos que deram origem à Lei Contra a Compra de Votos e à Lei da Ficha Limpa (no caso desta última, foram necessários três anos para que a quantidade mínima de assinaturas fosse alcançada e a iniciativa fosse encaminhada à Câmara).

Para assegurar a autenticidade das assinaturas digitais, o aplicativo exige que dados e documentos dos usuários sejam compatíveis (nome, data de nascimento, cidade, CPF e título de eleitor), de acordo com as normas definidas pela Câmara e outras Assembleias Legislativas. As informações passam por um processo de pseudonimização para garantir o sigilo, permitindo a privacidade dos assinantes, ao mesmo tempo que oferece a possibilidade de verificação das assinaturas pelo governo e pela sociedade civil. A ferramenta utiliza o blockchain, tecnologia aberta adotada por instituições financeiras para garantir a segurança e legitimidade de seus dados e de seus clientes, assim como para criptografar o bitcoin (moeda digital descentralizada): “Em um momento político complexo como o que atravessamos no Brasil, MUDAMOS usa a tecnologia para convocar a sociedade para encontrar respostas a desafios públicos, aumentando a participação democrática" (Mudamos, 2017). 
Apesar de atualizar o mecanismo constitucional que regulamenta os projetos de lei de iniciativa popular, a tecnologia enfrenta controvérsias no que tange à validade de assinaturas coletadas por meios eletrônicos, ou seja, para que possam ser integradas ao processo legislativo elas ainda precisam ser efetivamente regulamentadas e aceitas pelas Câmaras Municipais, Assembleias Estaduais e a Câmara dos Deputados. O jurista Márlon Reis garante que o MUDAMOS é completamente válido do ponto de vista legal: "a Constituição fala apenas em subscrição ao projeto, e não sobre o meio de coleta das assinaturas". De fato, o $\S 2^{\circ}$ do artigo 61 emprega a expressão "subscrito", abrindo margem para formas alternativas de reunir as assinaturas (Instituto Millenium, 2017).

A Câmara Municipal de João Pessoa (CMJP) foi a primeira casa legislativa brasileira que reconheceu oficialmente a possibilidade da apresentação de leis de iniciativa popular através do aplicativo MUDAMOS. O pioneirismo da cidade de João Pessoa se manifestou das seguintes formas: 1) Em julho de 2015, a CMJP sancionou a Lei 13.041/2015 que estipula que projetos de iniciativa popular podem ser feitos de forma eletrônica; 2) Em 09 de maio de 2017, com a adoção do aplicativo MUDAMOS, a lei municipal pode ser de fato efetivada. Em uma entrevista concedida para este trabalho ${ }^{6}$, Debora Albu, pesquisadora de democracia do ITS Rio, aponta o mérito da sociedade civil na inovação legislativa desta cidade, indicando que a CMJP foi apenas um dos autores da iniciativa institucional. O que houve em João Pessoa foi a combinação de uma sociedade civil engajada, da abertura do poder público e das possibilidades que a inovação tecnológica oferece.

O ITS Rio tem trabalhado para reproduzir a experiência desenvolvida em João Pessoa, se reunindo com outras casas legislativas brasileiras para que normatizem a forma eletrônica das assinaturas. O Instituto dispõe-se a assessorar estas casas com apoio técnico e jurídico-legislativo para regulamentar o entendimento de subscrição de leitores, compartilhando sua tecnologia e modelos de atos legislativos que materializem um novo cenário para iniciativa popular no Brasil.

Apontamos que a construção coletiva de políticas públicas é apenas um dos objetivos inicialmente estabelecidos pelo MUDAMOS. A plataforma digital também se propôs a ser um espaço virtual para discussão de temas de interesses comuns. Entretanto, em entrevista concedida a esta pesquisa, os técnicos do ITS Rio revelaram ter encontrado obstáculos na Internet para

6 Realizamos uma entrevista em 28 de fevereiro de 2018 com os técnicos do ITS Rio: Debora Albu (pesquisadora de democracia), Marco Konopacki (coordenador de projetos) e Victor Vicente (coordenador de comunicação). 
a promoção de debates qualificados que combinassem multissetorialidade, multiplicidade de vozes e independência de narrativas. Para solucionar esta lacuna apresentada pelo aplicativo, em 20 de outubro de 2017 o ITS Rio, em parceria com a CMJP, realizou a primeira Virada Legislativa do país. A ideia era que, durante um dia inteiro, vereadores, representantes de órgãos públicos, pesquisadores e cidadãos se encontrassem para debater problemas e trocar conhecimentos relacionados a uma temática específica, além de juntos construírem iniciativas que pudessem se tornar projetos de lei de iniciativa popular a serem assinados através do aplicativo. Deste modo, a Virada Legislativa se constituiu como um espaço público para o debate informado entre vários setores da sociedade e o MUDAMOS, como um espaço virtual para a consolidação de projetos de lei previamente estabelecidos coletivamente.

O primeiro tema escolhido para o encontro foi a mobilidade urbana. Marco Konopacki, coordenador de projetos do ITS Rio, comentou que houve uma demonstração de interesse da população de João Pessoa pelas questões relativas à circulação de pessoas e aos sistemas de transporte: "Quando nós lançamos o aplicativo MUDAMOS, $70 \%$ das ideias enviadas pelos pessoenses tocavam no tema da mobilidade urbana". A expectativa do Instituto com o evento era a elaboração de um plano multissetorial (envolvendo a população, sociedade civil, pesquisadores da área, setor empresarial e governo) que pudesse trazer novas perspectivas para os problemas de mobilidade urbana na cidade de João Pessoa.

A Virada Legislativa - Desafio Mobilidade Urbana foi dividida em oito painéis (sensibilização, problematização, enunciação, definição dos termos, definição de comandos, testando a lei, publicação no app, e encerramento). Destacamos o painel da sensibilização (etapa na qual diferentes atores expuseram as suas perspectivas sobre o tema da mobilidade urbana em João Pessoa) e o da problematização (sugestão de ideias e comentários da população) ${ }^{7}$.

Por uma questão de espaço não iremos abordar as pautas debatidas no evento de forma minuciosa, no entanto, atentamos para a análise e críticas ao Plano Diretor de Mobilidade Urbana de João Pessoa que é o principal instrumento de planejamento dos sistemas de circulação e transporte, atendendo à Lei de Mobilidade Urbana brasileira que determina que é obrigatório para municípios com mais de 20.000 habitantes ter este tipo de planejamento. No Plano constam os objetivos e ações para os horizontes futuros da cidade (a médio e longo prazo, 10 e 20 anos,

7 Os dois painéis citados foram transmitidos pela TV Câmara de JP e estão disponíveis para visualização em https://goo.gl/6jw5cB 
respectivamente), além de estudos comportamentais - por quê, como se movem e para onde vão as pessoas em seus deslocamentos pelo espaço urbanofundamentais para o planejamento e a compreensão da mobilidade urbana. Também foram discutidos a atuação da Superintendência de Transportes e Trânsito de João Pessoa - SEMOB; a implementação do Projeto Caminho Livre de 2012 que, ao reduzir espaços de calçados e canteiros de importantes vias da cidade para a implementação do BRT (Bus Rapid Transit), contrariou as diretrizes estabelecidas pela PNMU em 2012; as funções da Frente Parlamentar de Mobilidade Urbana criada em maio de 2017; os projetos para o BRT e o VLT (Veículo Leve sobre trilhos).

Dentre os pontos mais urgentes apontados pela população no segundo painel estão a humanização da cidade a partir da criação de uma infraestrutura que incentive as pessoas a andarem a pé e o uso de transportes não motorizados, a padronização das calçadas, a necessidade de construção de uma malha cicloviária, o respeito aos ciclistas, a maior intermodalidade entre os transportes, as melhoras no sistema de bilhetagem urbana, a superlotação e a necessidade de manutenção do transporte público coletivo, além da necessidade da criação de uma campanha de informação das linhas, trajetos e horários dos ônibus.
Ao final do evento, cinco projetos de lei sobre mobilidade urbana, desenvolvidos por ONGs e cidadãos pessoenses, foram apresentados a uma mesa composta por vereadores da cidade que, por sua vez, diagnosticaram possíveis problemas constitucionais por vícios e sugeriram possíveis caminhos para tornar as iniciativas mais eficazes. Os cinco PLs foram disponibilizados para consulta e assinatura no aplicativo cerca de dez dias após o evento ${ }^{8}$ :

\section{Lei do Transporte Público Aberto:} propõe dar acesso a informações de forma fácil e transparente sobre as linhas e trajetos dos ônibus na cidade. O projeto pretende alterar a lei que criou a Superintendência de Mobilidade (SEMOB) da cidade para regulamentar os dados que ela deve disponibilizar aos cidadãos e a maneira como esses dados devem estar disponíveis.

2. Lei de Aperfeiçoamento do Sistema de integração Temporal: Propõe aumentar o tempo para que os usuários façam a baldeação, além de estender a integração para todas as linhas de transporte público.

3. Lei da Empresa Amiga do Ciclista: propõe a instituição do programa "Vou de Bicicleta" e o "Selo Empresa Amiga do Ciclista". Procura fomentar o uso da bicicleta como alternativa de trans-

8 Todos os projetos de leis estão disponíveis em: https://goo.gl/MR3xFg 
porte por meio do oferecimento de incentivo fiscal para empresas que construam bicicletários e vestiários apropriados em suas instalações.

4. Lei de Integração Ônibus-Bicicleta: Pensando na construção de uma malha de transportes diversificados e conectados, propõe a integração da bicicleta com o sistema de ônibus coletivos a partir da fixação obrigatória de suportes para bicicletas nos ônibus em João Pessoa.

5. Lei de Padronização das Calçadas: Tendo em vista garantir a qualquer pessoa o direito de se deslocar pelo espaço público urbano de forma livre e autônoma, aponta as normas existentes que precisam ser respeitadas; o processo de fiscalização desse espaço urbano, as ações de informação e a conscientização dos cidadãos, cidadãs e poder público, envolvidos no processo de uma cidade melhor; além dos prazos e formas de readequação das calçadas fora das especificações exigidas.

A Lei Orgânica do Município de João Pessoa, em seu artigo 31, prevê que é necessário coletar as assinaturas de $1 \%$ dos eleitores pessoenses para a apresentação de projeto de lei de iniciativa popular à Câmara Municipal, ou seja, 5.176 assinaturas de um total de 517.607 eleitores aptos a votar em 2018 (Tribunal Superior Eleitoral, 2018). Embora esse número seja relativamente baixo, o aplicativo tem encontrado obstáculos no engajamento da população local em subscrever-se aos projetos. Conforme dados coletados do MUDAMOS em 01 de outubro de 2018, a Lei do Transporte Público Aberto conta com apenas 510 assinaturas; a Lei de Aperfeiçoamento do Sistema de Integração Temporal com 433; a Lei da Empresa Amiga do Ciclista com 373; a Lei de Integração Ônibus-Bicicleta com 408 e a Lei de Padronização das Calçadas com 551. De acordo com a informação concedida pelo ITS Rio, o MUDAMOS conta atualmente com 2842 cadastros completos de habitantes da cidade de João Pessoa. O baixo índice de participação -aproximadamente $0,55 \%$ dos eleitores pessoenses- nos revela um número de cadastro ainda insuficiente para o alcance do número mínimo de assinaturas para a viabilização dos projetos de lei de iniciativa popular propostos naquela cidade.

$\mathrm{Na}$ entrevista conduzida pela pesquisa, questionamos os técnicos do ITS sobre as possíveis causas para o problema. Victor Vicente, coordenador de comunicação, nos revelou que a territorialização do debate político nas cidades tem sido um dos maiores desafios do MUDAMOS. Marco Konopacki indica que a existência de uma sociedade civil forte e atuante não é automaticamente convertida em uma mobilização de massa. De acordo com Debora Albu, para que o potencial da ferramenta seja de fato explorado -trazendo uma maior representação popular para o campo político-é necessário, por exemplo, garantir um maior acesso à tecnologia (possuir um smartphone, ter conexão à Internet e saber como utilizar os dispositivos - literacia digital), além de promover a informação 
sobre o aplicativo e os projetos de lei aos diversos públicos (incluindo os grupos identitários marginalizados).

É oportuno também avaliarmos as possibilidades de implementação de outras iniciativas que visem uma maior atuação da sociedade civil nos espaços públicos virtuais. Neste sentido, problematizamos o papel das empresas midiáticas para dar visibilidade às ferramentas e às possibilidades de financiamento para a execução dos projetos. Segundo Weinhardt (2017), no caso do MUDAMOS não podemos menosprezar o capital social dos seus idealizadores -Márlon Reis e Ronaldo Lemos (diretor do ITS Rio)- que tem proporcionado ao aplicativo uma ampla cobertura nos circuitos midiáticos, além do capital financeiro recebido como prêmio do Desafio de Impacto Social Google 2016. Konopacki nos sugeriu em entrevista que o sucesso do aplicativo é multidimensional, pois é resultado de um somatório de elementos, tais como a inovação tecnológica proposta pela plataforma, a competência técnica de seus realizadores (e da equipe do ITS Rio como um todo), além da capacidade de financiamento, amplitude, engajamento e redes de comunicação nas quais os atores estão inseridos.

\section{Considerações Finais}

A análise da atuação do aplicativo MUDAMOS no debate e na construção coletiva de soluções para questões de interesses comuns revela que a conversão dos ambientes de sociabilidade digital em espaços públicos virtuais esbarra em algumas limitações. Observamos que a midiatização das relações; encontros e trocas que são estabelecidos cotidianamente nas ruas, praças, jardins, cafés e bares das cidades; exclui elementos fundamentais para a vinculação do tecido social urbano. Reconhecemos as inúmeras vantagens que as tecnologias da comunicação e da informação oferecem para a sociabilidade e as práticas políticas contemporâneas, tais como a possibilidade de produção de narrativas e o grande volume de interações, que fortalece a atuação da sociedade civil em questões de políticas públicas. No entanto, estes benefícios precisam ser acompanhados por reflexões críticas e soluções inovadoras para as possíveis perdas que o deslocamento das relações humanas das ruas para as redes engendra.

A partir de uma leitura gramsciana, compreendemos o aplicativo MUDAMOS como um mediador -uma ponte- entre representados e representantes do poder público no novo ecossistema existencial que Sodré (2002, 2014) define como "midiatização generalizada" ou "bios virtual". A plataforma digital atua como um espaço virtual para a construção coletiva de políticas públicas, ao mesmo tempo que promove encontros presenciais para contornar obstáculos impostos pela Internet no que tange à realização de debates qualificados que combinem heterogeneidade de grupos, multiplicidade de vozes e pluralidade de narrativas. Segundo Konopacki, o MUDAMOS é 
um primeiro canal efetivo de influência sobre uma esfera do poder público que é o Poder Legislativo. É preciso ainda uma maior interconexão entre as diferentes esferas do poder público e a sociedade civil como um todo.

Pensando as cidades a partir de uma perspectiva comunicacional, observamos que tanto as questões de comunicação quanto as de transportes podem ser analisadas como "redes" de infraestruturas que permitem, ou inibem, diferentes modos de atividade para diversificados setores da população (Morley, 2017). Neste sentido, as várias maneiras de circular nas cidades implicam em uma pluralidade de possibilidades de interagir e conectar com os espaços e corpos, isto é, uma multiplicidade de formas de organização do comum (Carmelini, 2017). Dessa forma, as políticas que regulam o deslocamento urbano, ao estimularem a livre circulação e facilitarem os acessos aos espaços comuns, estariam agindo para a humanização das cidades a partir da potencialização da diversidade dos encontros, das trocas e da vinculação social.

\section{Referências}

Bakhtin, M. (1992). Os Gêneros do Discurso - Estética da Criação Verbal. São Paulo: Martins Fontes.

Barbosa, M. (2016). A Pluralidade de Modelos Interpretativos nas Ciências Humanas e o Lugar da Comunicação. Em C. Moura e L. de Vassalo (Eds.), Pesquisa em Comunicação: Metodologias e Práticas Acadêmicas. Porto Alegre: EDIPUCRS.

Bianchi, A. (6 de abril de 2017). Introdução ao Dossiê Gramsci, Diálogos Inéditos: os Novos Estudos e a Recepção de seu Pensamento na Atualidade. Revista CULT 222(20).

Blume, B. (2015). Projetos de Iniciativa Popular que Viraram Leis. Politize. Recuperado de https://goo.gl/gGvUcc

Caiafa, J. (2017). Editorial Comunicação Urbana. Revista ECO-Pós - Dossiê Comunicação Urbana, 20(3), 1-9. Recuperado de https://goo.gl/BgY8yY

Carmelini, L. (2016). Corpo-Cidade-Bicicleta: Circulação Urbana e Política de Pedalar (Dissertação de Mestrado). Universidade Federal do Rio de Janeiro, Rio de Janeiro, Brasil.

Carmelini, L. (2017) Uma Abordagem Comunicacional da Circulação Urbana. Em XVII Encontro dos Grupos de Pesquisas em Comunicação - INTERCOM, Curitiba (pp. 1-14). Recuperado de https://goo.gl/pa1FWX

Código de Trânsito Brasileiro (23 de setembro de 1997). Lei 9.503. Recuperado de https:// goo.gl/yrjI2 
Coutinho, C. N. (1989). Gramsci: um Estudo sobre seu Pensamento Político. Rio de Janeiro: Editora Campus

Coutinho, C. N. (2011). O Leitor de Gramsci: Escritos Escolhidos (1916-1935). Rio de Janeiro: Civilização Brasileira

Coutinho, E. G. (2014). Gramsci: a Comunicação como Política. Em E. G. Coutinho, A Comunicação do Oprimido e Outros Ensaios (pp. 27-41). Rio de Janeiro: Mórula.

Constituição da República Federativa do Brasil. (1988). Recuperado de https:/goo.gl/ HwJ1Q

Dardot, P., e Laval, P. (2017). Comum: Ensaio sobre a Revolução no Século XXI. São Paulo: Boitempo.

Estatuto da Cidade. (10 de julho de 2001). Lei 10.257. Recuperado de https:/goo.gl/ SvFKDs

França, V. V. (2016). O Objeto e a Pesquisa em Comunicação: uma Abordagem Relacional. Em C. Moura e L. de Vassalo de (Eds.), Pesquisa em Comunicação: Metodologias e Práticas Acadêmicas 153-174. Porto Alegre: EDIPUCRS.

Gabbay; M., e Paiva, R. (2017). Uma Nova Cidade Humana: Cidadania e Comunicação Contra a Barbárie (2017). Em XXVI Encontro Anual da COMPÓS, São Paulo, (pp.1-13). Recuperado de https://goo.gl/yZ5oAv

Gramsci, A. (1999-2002). Cadernos do Cárcere. Edição e tradução de Carlos Nelson Coutinho (v. 1, 2, 3, 4, e 6). Rio de Janeiro: Civilização Brasileira.

Instituto Millenium. (2017). Aplicativo Torna Mais Fácil Assinatura de Projetos de Iniciativa Popular. Recuperado de https://goo.gl/MMBRFo

Lei 9.709. (18 de novembro de 1998). Recuperado de https://goo.gl/NKFDri

Lei Orgânica do Município de João Pessoa. (20 de abril de 1990). Recuperado de https:// goo.gl/RZGvyx

Liguori, G., e Voza, P. (Eds.). (2017). Dicionário Gramsciano (1926-1937). São Paulo: Boitempo.

Morley, D. (2017). Comunicação e Transporte: a Mobilidade de Informação, de Pessoas e de Mercadorias. Revista ECO-Pós - Dossiê Comunicação Urbana, 20(3), 10-38. Recuperado de https://goo.gl/BgY8yY

Mudamos. (19 de abril de 2017). Sua Ferramenta para Construir a Democracia Digital. Em Página do MUDAMOS no Facebook. Recuperado de https://goo.gl/PR8U1T

Pacheco, P. (2013). Cidades Mais Humanas: Priorizando Pessoas. The City Fix Brasil. Recuperado de https://goo.gl/ZVQ6qb

Política Nacional de Mobilidade Urbana. (3 de janeiro de 2012). Lei 12.587. Recuperado de https://goo.gl/LEvQd 
Sodré, M. (2002). Antropológica do Espelho: Uma Teoria Linear e em Rede. Petrópolis, Rio de Janeiro: Vozes.

Sodré, M. (2014). A Ciência do Comum. Notas para o Método Comunicacional. Rio de Janeiro: Vozes.

Sodré, M. (2017). Pensar Nagô. Rio de Janeiro: Vozes.

Sodré, M. (2018). Ementa ao Curso A Sociedade Civil na ECO-UFRJ. Recuperado de https:// goo.gl/NfjUKi

Tribunal Superior Eleitoral. (2018). Recuperado de https:/goo.gl/YL98ws

Weinhardt. E. (2017). Novas Possibilidades para uma Democracia Participativa: um Estudo de Caso sobre o Aplicativo Mudamos. Em XVII Encontro dos Grupos de Pesquisas em Comunicação - INTERCOM, Curitiba (pp. 1-15). Recuperado de https://goo.gl/FHGac4 